\title{
DETERMINATION OF MATERIAL CHARACTERISTICS NECESSARY FOR MODELLING OF MARINE STRUCTURES EXPOSED TO SMALL-CALIBRE BULLET
}

\author{
Radosław Kiciński, Bogdan Szturomski, Wojciech Jurczak \\ Polish Naval Academy, Mechanical-Electrical Department \\ Smidowicza Street 69, 81-127 Gdynia, Poland \\ tel.: +48261262616 \\ e-mail:kicirad@gmail.com,bsztur@gmail.com \\ jurczak@amw.gdynia.pl
}

\begin{abstract}
The article presents the results of tests of impact properties of steel 1.3964 used on the construction of modern mine destroyers. Ships of this type, like any other military unit, may be exposed to small-calibre projectiles. Firing can be done, for example, from aircraft, drones or pirate units. The thickness of the plates used in the ship's construction does not guarantee effective resistance to the projectile calibre $7.62 \mathrm{~mm}$ for all compartments of such ships. Thus, it is possible to modify the existing structure or apply additional solutions that will ensure a certain level of ballistic resistance. Solutions of this type are necessary in order to maintain the stability and buoyancy of the ship at the current level. During the tests, a stress-strain curve for steel 1.3964 was obtained, then the Johnson-Cook plasticity and damage model was proposed, which was used in the FEM simulation. The task was modelled as non-linear considering the deformation of both the sample and the projectile. The simulation was prepared in the CAE program, and then verified by an experiment on the shooting range. The results were presented in the form of diagrams and deformation figures, and were compared with photographs of samples and velocities after the specimen.
\end{abstract}

Keywords: sea constructions, CAE, marine mine destroyer

\section{Introduction}

The thickness of the ship's plating depends on their purpose. In extreme cases, it can range from $3 \mathrm{~mm}$ for a minesweeper up to $650 \mathrm{~mm}$ on the "Yamato" battleship from 1941. With the development of the quality of manufactured steel and the changes in the concept of war at sea (reduction in the use of artillery), the thickness of the sheets has changed and now varies from 3 to $20 \mathrm{~mm}$. Polyester-glass laminates are also used to reduce the magnetic field of the ship.

Due to the fact that ships are often modernized, constructors are not able to predict appropriate solutions in the initial phase of the project. It happens that during modernization, combat information centres, weapon warehouses, etc. can be found in compartments that show almost no bulletproofness. In addition, for ships, an important parameter is the mass above the centre of gravity. The diametric increase in the thickness of the plating in the compartment causes the weight to increase above the centre of gravity, which affects the stability of the ship. For this reason, solutions are sought that will allow to increase the puncture resistance with a small increase in the weight of the entire ship. The solution may be spaces between the ship's shell and a protected compartment that can be filled with air or other absorbent material. This article presents the influence of the thickness of the tested steel on penetrations with a $7.62 \mathrm{~mm}$ small calibre bullet.

\section{Determining the nominal characteristics of 1.3964 austenitic steel}

Material characteristics were obtained from a static tensile test in accordance with PN-EN ISO 6892-1: 2016-09. Due to the high strength and hardness of the tested steel, the sample areas were cut from its sheet (parallel and perpendicular to the rolling direction) using water jet cutting. 
Steel 1.3964 is austenitic stainless steel with the symbol: EN/DIN X2CrNiMnMoNNb 21-16-5-3. Its strength depends on the type of treatment at the metallurgical stage. Using cold hardening or hardening, it allows obtaining tensile strength of 700-950 MPa. Steel 1.3964 is fully weldable; however, it has strict rules regarding the welding technology used and the choice of chemical composition of the binder (1.3954 or 1.3984).

A static tensile test was carried out on a MTS testing machine with digital registration and computer control, operating in the tensile force range up to $100 \mathrm{kN}$ at a relative tensile speed of $\dot{\varepsilon}=10^{-3} \mathrm{~m} / \mathrm{s}$ in accordance with PN-EN ISO 6892-2: 2011.

Carrying out engineering calculations of a plastic-elastic material requires the preparation of a real characteristic $\sigma_{\text {true }}=f\left(\varepsilon_{\text {true }}\right)$. This is caused by the problem that occurs in the nominal characteristic, which results from the adoption of the initial cross-section $A_{0}=$ const. This assumption makes it impossible to use it in numerical analyses. It is known that the cross-section of the sample is reduced during the test. In the Young's module operating range, the changes in the cross-section are not taken into account due to slight changes. Meanings acquire in the situation of crossing the yield point, where the speed of change of the cross-section area increases. Real stresses are defined by the dependence of $A(F)$, the tensile force $F$ on the cross-sectional area of the sample depending on this force at a given moment. At the time of breaking, section measurement is troublesome to perform and only modern positions (e.g. digital image correlation) are able to realize the measurement of the actual narrowing. The preparation of the actual characteristics is based on the principle of calculations that take into account physical and geometric factors. A detailed description of the calculations is available in the literature [1] and will be omitted in this publication.

Figure 1 shows the nominal characteristics for round samples, austenitic steel 1.3964. On the basis of the tests, the mechanical properties of the tested steel were determined, the strength limit $R_{m}=1125 \mathrm{MPa}$ and the yield stress $R_{e}=390 \mathrm{MPa}$. The strength properties are similar for all samples of the steel tested, irrespective of the method of drawing from the sheet metal in relation to the rolling direction. The samples are distinguished by showing a lower strain, on average by $30 \%$, for samples taken perpendicular to the rolling direction. Another noticeable element in the graphs obtained from MTS is the fact that the longitudinal samples have a distinct yield stress $R_{e}$, which value is lower by $38 \mathrm{MPa}$ from the conventional yield point $R_{0.2}$ for samples taken perpendicular to the direction of rolling.

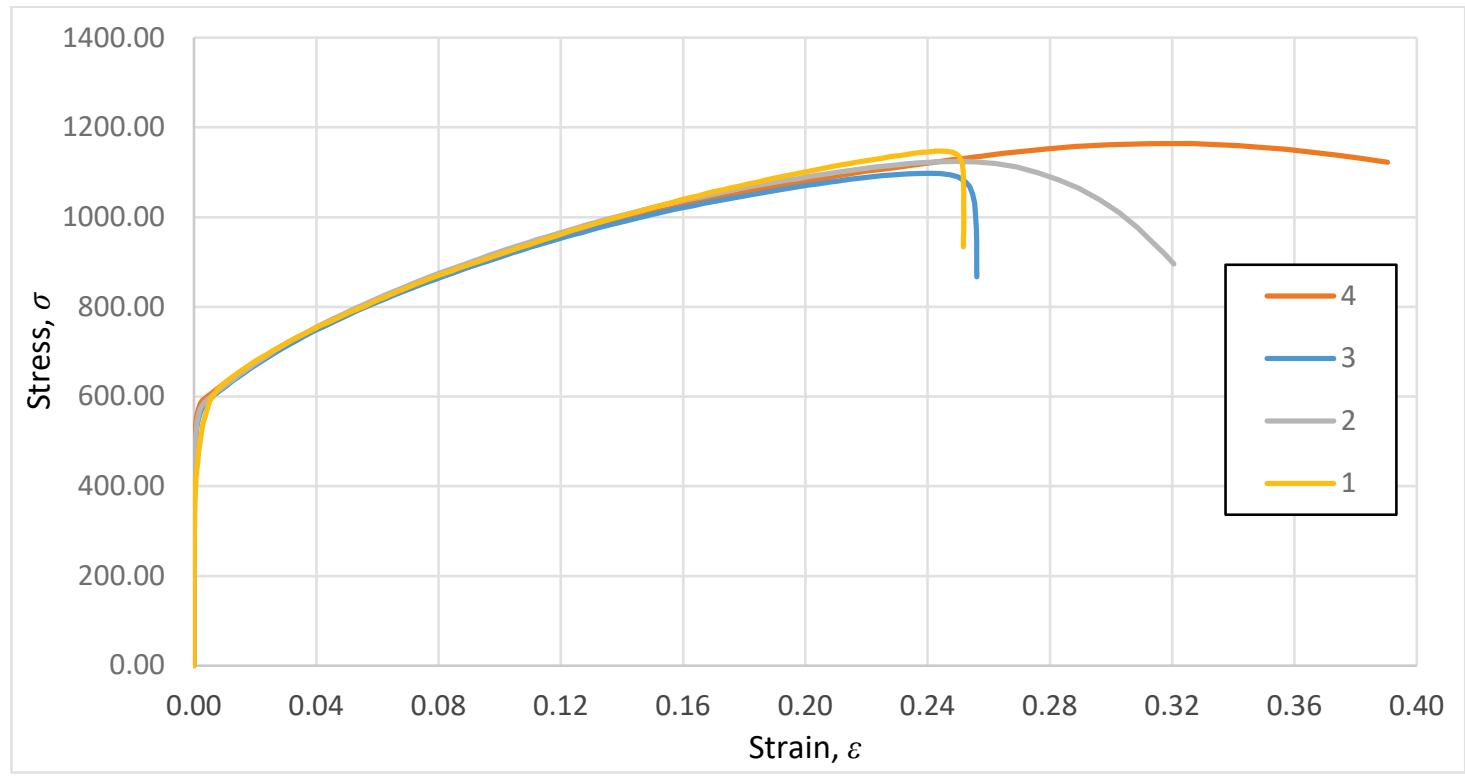

Fig. 1. List of nominal characteristics from static tensile test of steel 1.3964 for round samples taken: along the rolling direction $(1,3)$, perpendicular to the rolling direction $(2,4)$ 
In CAE programs, inputting material data using a table is cumbersome and results in extended calculations due to extrapolation between curve points. This problem can be circumvented using material models. In fast-changing processes, such a material can be described using the JohnsonCook polynomial in the form [2]:

$$
\sigma=\left(A+B \varepsilon^{n}\right)\left(1+C \ln \left(\frac{\varepsilon}{\varepsilon_{0}}\right)\right)\left(1-\frac{T-T_{0}}{T_{m}-T_{0}}\right)^{m}
$$

where:

$\sigma-$ stresses in the material,

$A$ - material constant,

$B$ - strengthening parameter,

$\varepsilon \quad$ - reduced plastic deformation,

$n$ - exponent of the strengthening,

$C$ - material sensitivity coefficient for strain rate,

$\dot{\varepsilon}$ - reduced speed of plastic deformation,

$\dot{\varepsilon}_{0}$ - deformation speed threshold,

$T$ - temperature at which the material will work,

$T_{0}$ - ambient temperature,

$T_{m}$ - melting point,

$m$ - exponent of softening under the influence of temperature.

The obvious drawback of the static tensile test is the inability to determine the impact of deformation velocity on the properties of steel. In addition, no temperature change studies have been carried out in this publication. Considering the above, the appropriate material parameters were adopted, omitting the temperature constants, which are presented in Tab. 2.

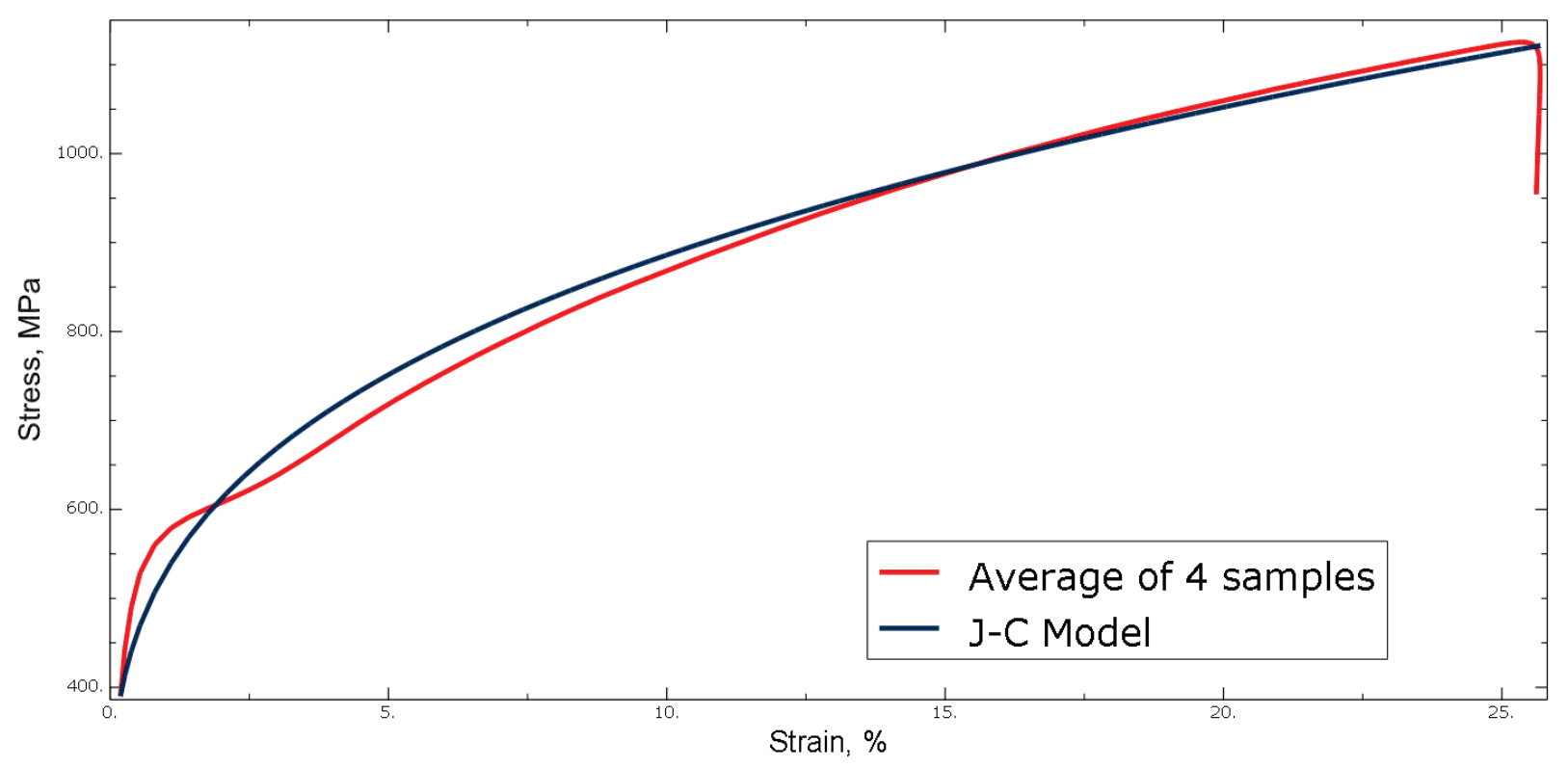

Fig. 2. Comparison of the proposed J-C material model with the average of the test results

\section{Determination of the damage criterion}

The next stage of the work was to determine the damage criterion. Numerous models of destruction have been described in the literature; however, due to the fact that the characteristics for increased deformation velocities have not been determined, this article uses a simplified model of Johnson-Cook destruction in the form of: 
where:

$$
\bar{\varepsilon}_{D}^{p l}=\left[d_{1}+d_{2} \exp \left(-d_{3} \eta\right)\right]
$$

$d_{1} \quad$ - deformation for which the tensile strength limit was adopted,

$d_{2}, d_{3}$ - material constants describing the softening of the material,

$\eta \quad-$ triaxiality.

In order to determine the appropriate value of the destruction criterion, field tests were carried out. The tests consisted of shooting samples with a thickness of 4, 6, 8 and $10 \mathrm{~mm}$ (folded sample $6+4)$. The tests were carried out on 13-14.05.2019 at Zakłady Mechaniczne Tarnów S.A. Based on the results, a graph of decrease in the projectile velocity after the sample as a function of thickness was created. The tests were carried out on samples whose measuring part was square with a side equal to $100 \mathrm{~mm}$. The projectile velocity was measured before and after the sample. It was assumed that the difference in speed is the result of a decrease in the total energy absorbed by the material in the form of friction and any accompanying phenomena.

The next step was to choose material constants in such a way that they would agree with the results of the experiment. For this purpose, a sample and projectile model was created. Then, a series of simulations were carried out, which allowed to determine material constants and the appropriate coefficient of friction. The simulation was prepared as a fully non-linear problem dependent on the deformation of both the material being tested and the projectile. Material data for the projectile was obtained from the literature [4] and presented in Tab. 1. The projectile was discretized using 3184 elements of C3D8R and C3D6. The sample model was prepared and discretised in such a way that the size of the finite elements at the point of contact with the projectile was $L=0.0005 \mathrm{~m}$, the sample model consisted of C3D8R elements.

Tab. 1. Material properties for the shell and core of the projectile

\begin{tabular}{|c|c|c|c|c|c|c|c|}
\hline & \multicolumn{4}{|c|}{ J-C plasticity } & \multicolumn{3}{c|}{ J-C damage } \\
\cline { 2 - 8 } & $A[\mathrm{MPa}]$ & $B[\mathrm{MPa}]$ & $n$ & $C[5]$ & $d_{1}$ & $d_{2}$ & $d_{3}$ \\
\hline Core & 234.4 & 413.8 & 0.25 & 0.0033 & 5.625 & 0.3 & -7.2 \\
\hline Shell & 448.2 & 303.4 & 0.15 & 0.0033 & 2.25 & 0.0005 & -3.6 \\
\hline
\end{tabular}

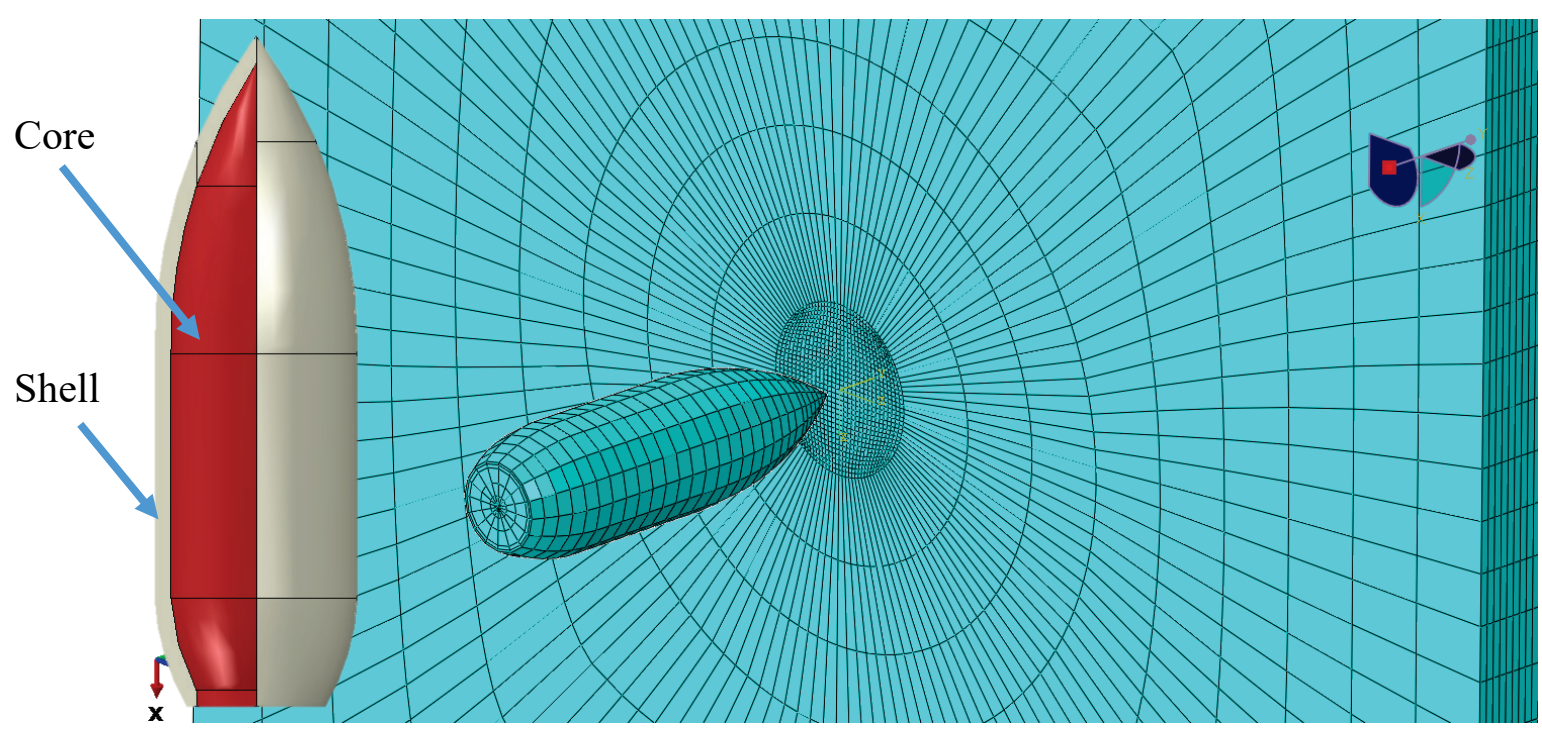

Fig. 3. Geometry and discretization of the task

Comparing simulation results with the experiment, material constants were determined for use in engineering calculations. The coefficients are presented in Tab. 2. In addition, an additional $u_{\text {failure }}$ 
parameter was included, which depend on the length of the characteristic FEM element. In the model, the evolution of destruction was simulated as linear and described by the dependence:

$$
\bar{u}_{\text {failure }}^{p l}=L \bar{\varepsilon}_{D}^{p l} \text {. }
$$

Tab. 2. Material constants for 1.3964 steel

\begin{tabular}{|c|c|c|c|c|c|c|c|c|}
\hline & \multicolumn{4}{|c|}{ J-C plasticity } & \multicolumn{5}{c|}{ J-C damage } \\
\cline { 2 - 10 } & $A[\mathrm{MPa}]$ & $B[\mathrm{MPa}]$ & $n$ & $C[5]$ & $d_{1}$ & $d_{2}$ & $d_{3}$ & $u_{\text {failure }}$ \\
\hline 1.3964 & 180 & 1425 & 0.305 & 0.006 & 0.025 & 0.005 & 1.5 & 0.00025 \\
\hline
\end{tabular}

\section{Results}

A series of simulations were carried out with reference to the polygon experiment. The speed of the projectile after the sample and deformations from the simulation with the actual strains of the samples was compared. The results were compiled in the form of photos and drawings.

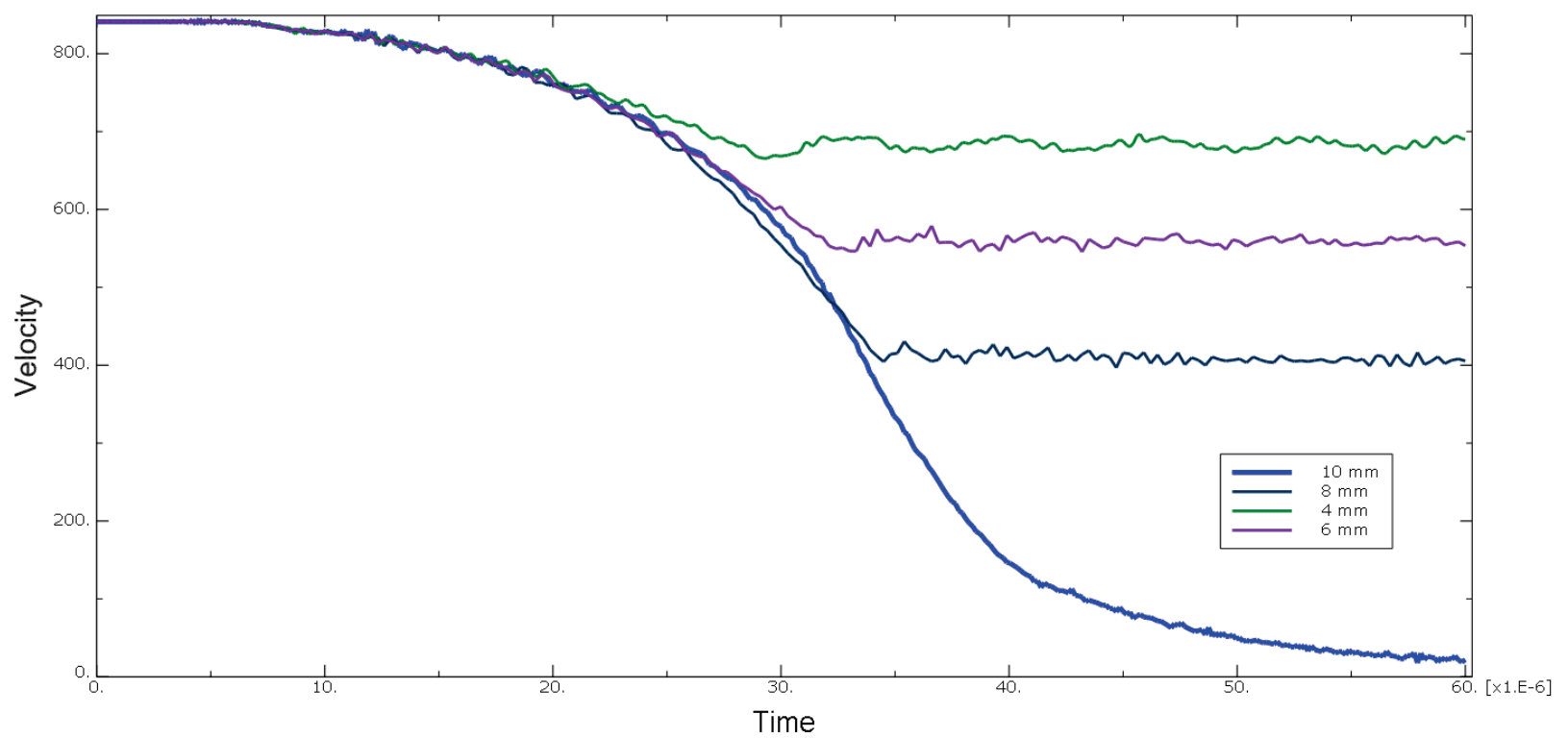

Fig. 4. Graph of projectile velocity drops for different thickness of samples

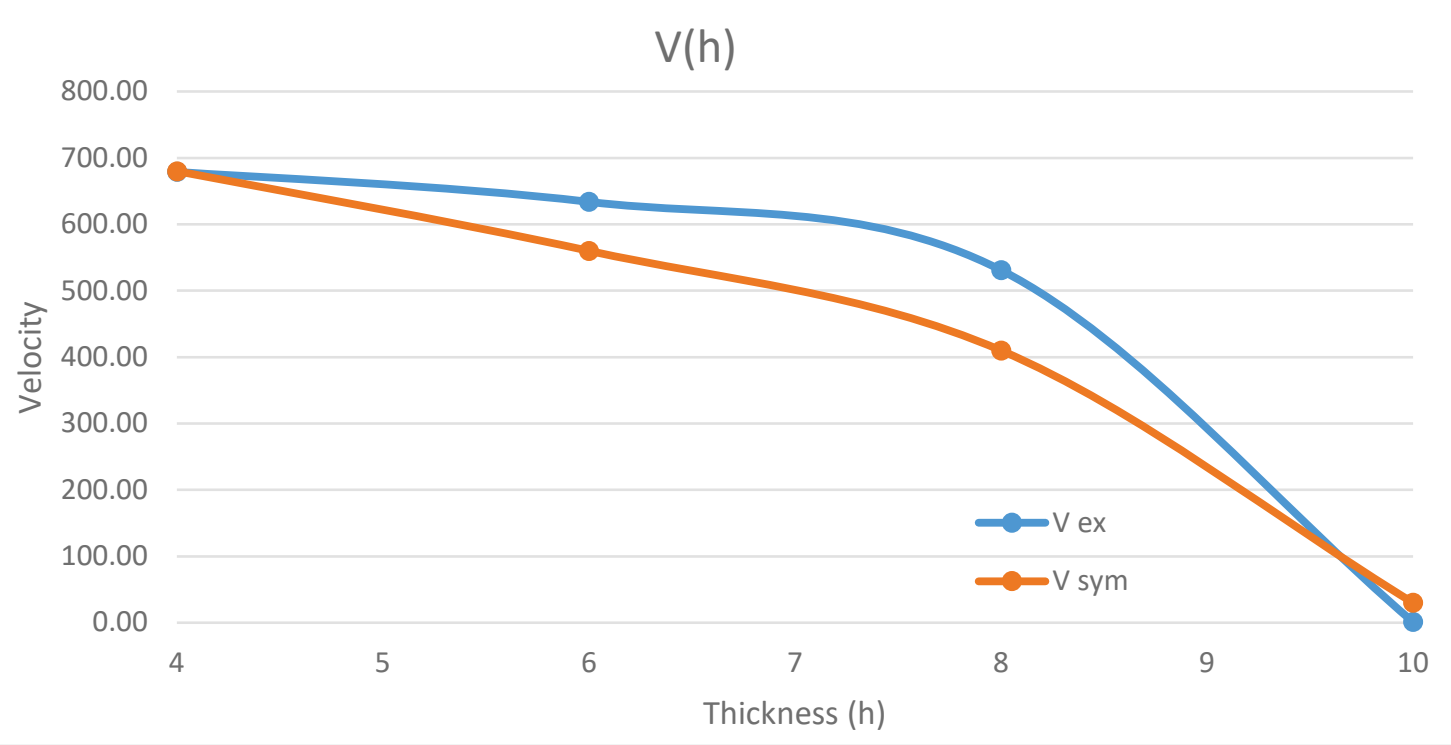

Fig. 5. Comparison of speed drops results from an experiment with simulation results 


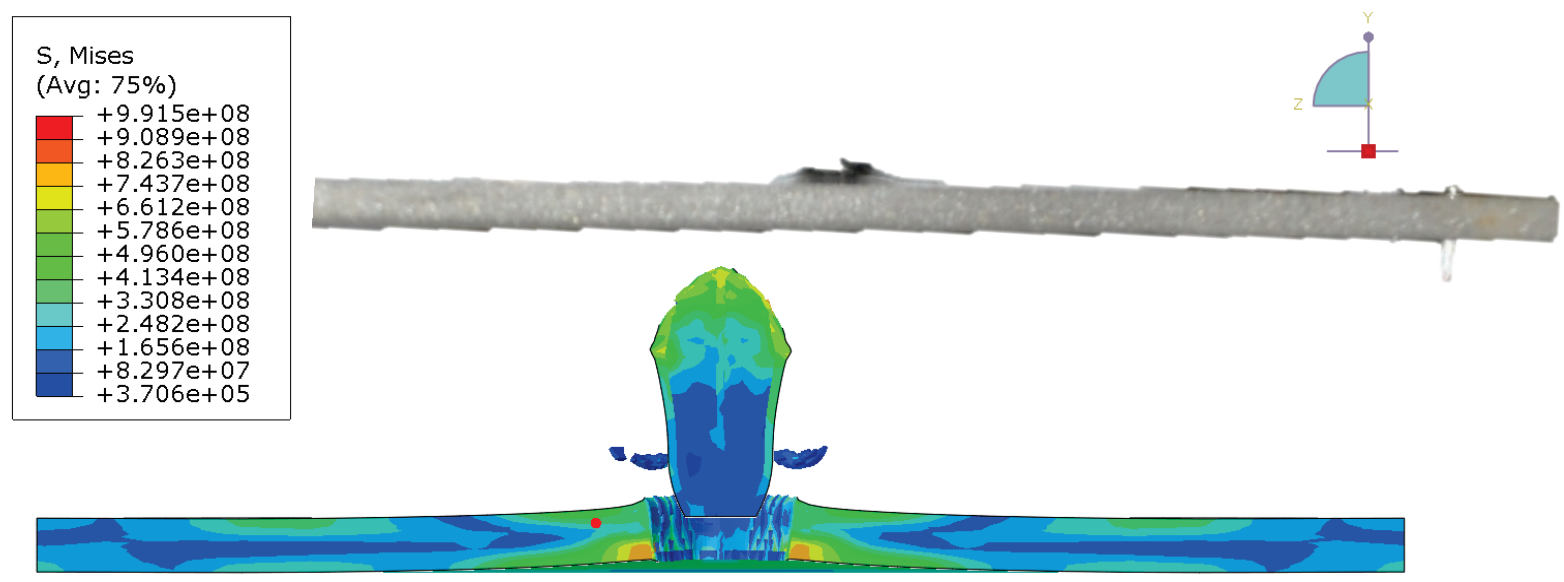

Fig. 6. Simulation of penetration of a $4 \mathrm{~mm}$ sample
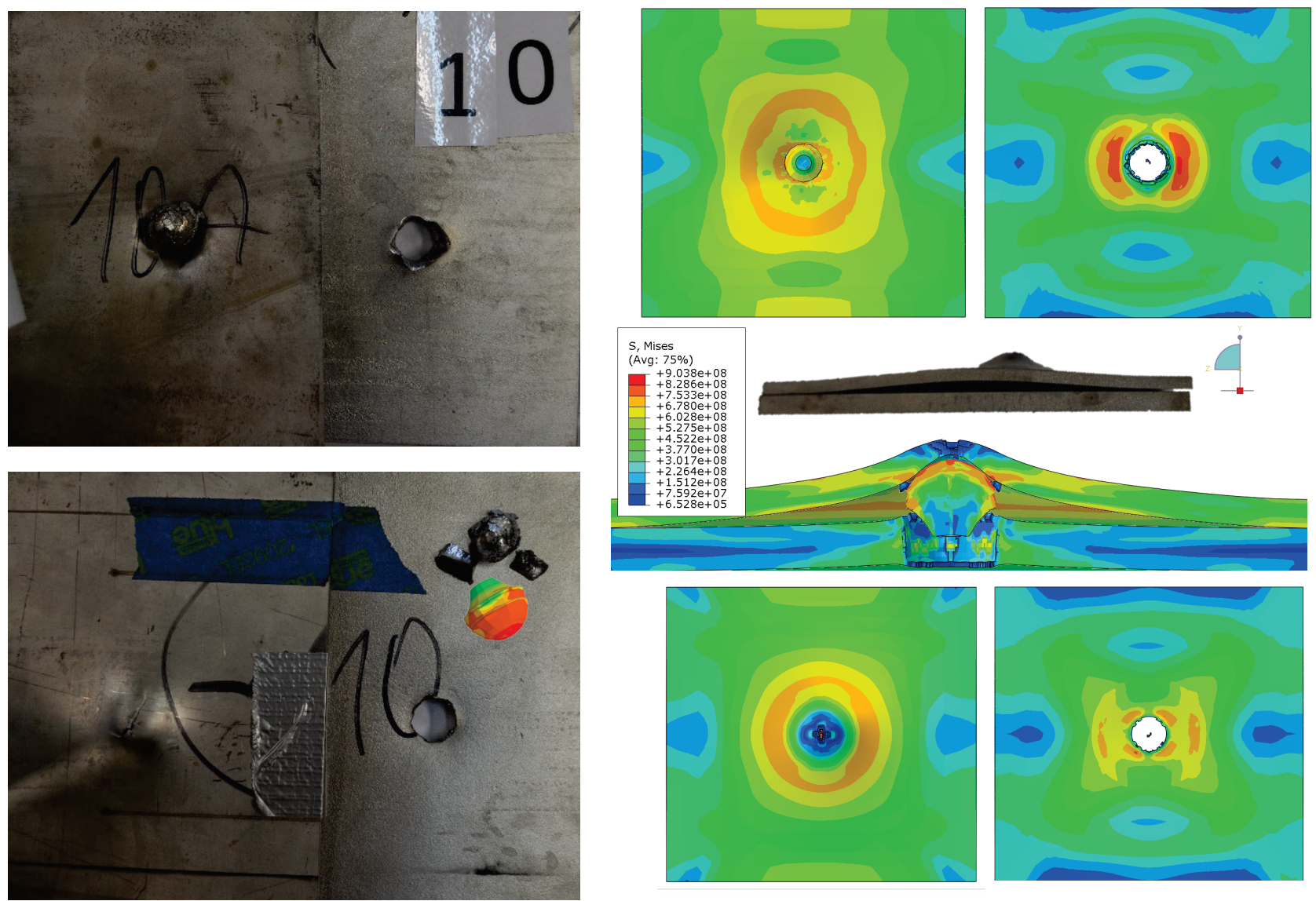

Fig. 7. Simulation of penetration of a $10 \mathrm{~mm}$ sample

\section{Summary and conclusions}

The article presents the material model used for numerical simulations. Material characteristics, based on literature and own tests from a testing machine, are presented. The next step was to choose simulation conditions and appropriate damage criteria in such a way as to achieve the convergent results. The data obtained in this way will be used to design a lightweight ballistic shield for use in shipbuilding.

Based on the results of the experiment and simulation, material constants were selected in such a way as to reflect the behaviour of the steel for penetration with a small calibre bullet. Differences 
ranged from $0.15 \%$ to $22 \%$ (Fig. 5), which is an acceptable result for such a non-linear issue. Simulations made for uniform sheets $(4.6$ and $8 \mathrm{~mm}$ ) did not require the use of a coefficient of friction. This coefficient was chosen at the level of $\mu=0.5$, only for combined samples (Slow speed drop for a $10 \mathrm{~mm}$ sample in Fig. 4).

The work presents the contact issue of fully deformable bodies. This requires the use of complex FEM operations that define contacts between each of the model elements. In addition, the use of damage criteria creates new contacts in each time step. Considering the above, it can be assumed that differences in results at the level of $22 \%$ are acceptable and allow the model to be used for further calculations.

The model tends to linearly decrease in speed when the thickness is increased (Fig. 5), therefore for a greater material thickness; the coefficient of friction should be taken into account.

The proposed damage criterion is sufficient for the calculation of the penetration of a smallcalibre bullet; however, you must be aware that other types of loads may cause other deformation results.

\section{Acknowledgments}

Scientific work financed from the "RESEARCH GRANT" program implemented in accordance with the assumptions of the Priority Research Directions in the Ministry of National Defence for 2013-2022 described by the code M-1-1-1-021 / 20018.

\section{References}

[1] Szturomski, B., Modelowanie oddziaływania wybuchu podwodnego na kadtub okrętu w ujęciu numerycznym, Wydawnictwo AMW, 2016.

[2] Johnson, G. R., Cook, W. H., A Constitutive model and data for metal subjected to large strains, high strain rates and high temperatures, Proceedings of the 7 th International Symposium on Ballistics, 2009.

[3] Abaqus, 6.10, PDF Documentation, Theory Manual, Simulia, Dassault Systems, 2010.

[4] Carbajal, L., Jovicic, J., Kuhlmann, H., Assault Riffle Bullet-Experimental Characterization and Computer (FE) Modeling, Conference proceedings of the Society for Experimental Mechanics Series, Experimental and Applied Mechanics, 1007/978-1-4614-0222-077, 2011.

[5] Szturomski, B., Świątek, K., Jurczak, W., Determination of dynamic characteristics of austenitic steel to be utilized in fem simulation and its verification, Scientific Journal of Polish Naval Academy, LIX, 2018. 